\title{
El Plan de Casa Mata y el federalismo en Nuevo León, 1823
}

\author{
Luis Jáuregui*
}

\section{Resumen}

El Plan de Casa Mata replanteaba la unión de las provincias del país con el centro. EI artículo revisa las características particulares de las Provincias Internas de Oriente, dadas en parte por su lejanía y en parte por el régimen de excepción con el que habían sido creadas. Muestra la rivalidad entre Saltillo y Monterrey por obtener la capital de la provincia, misma que dio lugar a su separación posterior y a las diferencias entre ellas y entre las ideologías de los hombres que las dirigían o manipulaban: fray Servando Teresa de Mier, Miguel Ramos Arizpe y Felipe de la Garza.

\begin{abstract}
The plan of Casa Mata proposed a new framework for the union of Mexican provinces with the political center. This article examines the particular features of the East Internal Provinces, determined partly by their remoteness and partly by the regime of exception by which they had been created. It shows the rivalry between Saltillo and Monterrey to become the capital of the province, which resulted in their eventual separation, as well as the differences between the ideologies of the men who commanded or manipulated them: Fra. Servando Teresa de Mier, Miguel Ramos Arizpe and Felipe de la Garza.
\end{abstract}

Palabras clave:

Nuevo León, Coahuila, Texas, federalismo, Diputación Provincial, Provincias Internas de Oriente, Miguel Ramos Arizpe, fray

Servando Teresa de Mier Noriega y

Guerra, independencia.
Fecha de recepción: febrero de 2000

Fecha de aceptación: octubre de 2000

*Investigador titular del área de Historia Económica del Instituto de Investigaciones Dr. José María Luis Mora. Correo electrónico: ljauregui@institutomora.edu.mx 
$\mathbf{E}$ n el año de 1821, cuando Nueva España se independizó de la monarquía española para convertirse en la nación mexicana, las diversas provincias que componían el antiguo virreinato se unieron voluntariamente -por conveniencia o porque no les quedaba otra opción ante la posibilidad de un vacío de poder y/o de reconquistabajo "un cuerpo de representación nacional [encargado] de interpretar[...] los sentimientos de las provincias". ${ }^{1}$ Este cuerpo fue, primeramente, la Junta Provisional Gubernativa, que poco tiempo después dio paso al Primer Congreso Constituyente.

Unos cuantos meses después de lograda la independencia, el poder ejecutivo de la nueva nación, ostentado como emperador por Agustín de Iturbide, encarceló a varios miembros de la representación nacional bajo el pretexto de que conspiraban en su contra, y disolvió el Constituyente. En su lugar estableció una nueva corporación -la Junta Nacional Instituyente- formada.por algunos miembros del Constituyente recién disuelto.

El resultado de este golpe de Estado sería la modificación de la opinión pública en contra del imperio; modificación que culminaría con su caída y con el establecimiento de una forma federada de gobierno. Así, por una parte, en diciembre de 1822 Antonio López de Santa Anna, apoyado por Guadalupe Victoria, Vicente Guerrero y Nicolás Bravo, se pronunció en el puerto de Veracruz. La proclama de Santa Anna exigía la nulidad del nombramiento de Iturbide y la reunión del

${ }^{1}$ Barragán Barragán, Introducción, 1994, p. 152.
Congreso en un punto libre que declarase la forma de gobierno que habría de establecerse; entretanto se observarían las garantías del Plan de Iguala y la Constitución española. ${ }^{2}$ El resultado de este pronunciamiento-modificado y con otros protagonistas- fue la promulgación del Plan de Casa Mata del primero de febrero de 1823; este plan, que tampoco proponía el establecimiento de una república, tendría efectos más duraderos. ${ }^{3}$ Su promulgación, dice el texto del plan, obedeció a que en México no existía representación nacional, por lo que era necesaria la instalación, a la mayor brevedad, de un congreso. Éste se formaría de los diputados del cuerpo legislativo que disolviera Iturbide en octubre de 1822 siempre y cuando éstos fueran, a juicio de las provincias, "de ideas liberales, firmeza de carácter y aprecio público". El ejército se erigía como defensor de la representación y de sus disposiciones, mientras que a la Diputación Provincial de Veracruz se le otorgaba el derecho de tomar decisiones de carácter administrativo, en tanto que determinaba si convenía a sus intereses la aceptación del plan por parte del supremo gobierno. ${ }^{4}$

2 Alamán, Historia, 1985, vol. 5, p. 690.

3 Mecham sugiere que el Plan de Veracruz "implicaba" una república. Mecham, Origins, 1938, p. 166. Este autor no está del todo en el error, pues Alamán mismo observa que había sido necesario proceder bajo otro plan (el de Casa Mata) con el que en último resultado se llegase al mismo objetivo, sin alarmar con el nombre de república a los que la temian. Alamán, Historia, 1985, vol. 5 , p. 705 (sin cursivas en el original).

${ }^{4}$ Jiménez, Planes, 1987, pp. 139-142, para el Plan de Veracruz, pp. 143-144, para el de Casa 
La promulgación y divulgación en todas las provincias del Plan de Casa Mata significó el replanteamiento de la unión entre éstas y el antiguo centro virreinal. De hecho, como dice Benson, a partir del triunfo del pronunciamiento iniciado en Casa Mata, mismo que estuvo marcado el 29 de marzo de 1823 por el ingreso a la ciudad de México de los antiguos diputados del Constituyente disuelto, y hasta la promulgación de la Constitución Federal en octubre de 1824,

la mayoría de las provincias de México mantuvo su propio gobierno independiente y $\tan$ sólo obedecieron los decretos del gobierno central por libre consentimiento de cada una de ellas [y, por su parte,] el gobierno central no $t$ [uvo] ya poder para obligar a las provincias o intendencias a que aceptaran sus decretos. ${ }^{5}$

En el norte de la naciente república la posición de las llamadas provincias internas revistió características particulares, debido principalmente a su lejanía con respecto a la ciudad de México y al régimen de excepción con el que habían sido creadas desde la segunda mitad del siglo XviII. ¿Cuáles fueron los acontecimientos que marcaron el camino hacia el federalismo en la zona noreste de México, específicamente en la provincia de Nuevo León entre la promulgación del Plan de Casa

Mata. Hasta el primer bimestre de 1823 México contaba con siete diputaciones provinciales, comandadas por un jefe político, que habían sido diseñadas como consejos administrativos y no legislativos. Green, Mexican, 1987, p. 36.

5 Benson, Diputación, 1994, p. 149.
Mata y las elecciones para el segundo congreso constituyente?, es la pregunta que se hace el presente trabajo.

Las conclusiones principales que arroja este ejercicio tienen que ver con las características propias de aquella región. Así, por una parte, la crisis de 1823 dio pie a una pugna entre Saltillo, capital de la proyectada intendencià de Coahuila, y Monterrey, asiento del obispado y de la tercera Diputación Provincial, electa pero no instalada, a inicios de 1822 . La rivalidad entre ambas ciudades, origen de la definición posterior de dos estados: Coahuila/Texas y Nuevo León," fue sin duda el reflejo de luchas entre oligarquías locales. Estas luchas se vieron elocuentemente expresadas en las estrategias de tres personajes de la política local: Miguel Ramos Arizpe, que en esos meses se hallaba en las provincias norteñas; fray Servando Teresa de Mier, miembro del Congreso restaurado en marzo de 1823 así como del Segundo Congreso Constituyente, electo en agosto de este año, y Felipe de la Garza, que en ocasiones se antoja como el títere de los dos primeros.

El resultado del análisis de los seis meses posteriores a la promulgación del Plan de Casa Mata muestra además las consecuencias de la lejanía con res-

${ }^{6}$ La colonia de Nuevo Santander se separó del esquema proyectado de una sola provincia de oriente; el hecho de que se comente poco sobre esta porción de México se debe a que su separación de las otras tres provincias generó pocos documentos, como lo señalara el padre Mier: "Santander no se ha dignado dar cuenta al gobierno de su [...] soberanía". Diez cartas, 1940, p. 14 (carta 4). 
pecto al centro político de México. Casi desde el principio, en la ciudad de México se tuvo la idea de que las provincias nororientales estaban buscando la virtual secesión del resto del país. Esta idea al parecer fue "alimentada" en la capital nacional por el padre Mier, quien la fomentaba desde la Diputación Provincial establecida en Monterrey. Esta idea, además, se percibía desde la ciudad de México ante la propuesta de Miguel Ramos Arizpe de un federalismo a ultranza. En cualquier caso, las diferencias de opinión motivaron múltiples recriminaciones y amenazas provenientes del centro, $\mathrm{e}$ incluso aquéllas fueron la ocasión de que, al menos en la ley, desde el centro se buscara la separación de Coahuila/Texas y Nuevo León.

\section{Las repercusiones del Plan de Casa Mata en Nuevo LeÓN}

Desde 1814, Nuevo León debía formar parte de una Diputación Provincial denominada Provincias Internas de Oriente que comprendía las provincias de Coahuila y Texas, el Nuevo Reino de León y la colonia de Nuevo Santander. Esta junta, reunida en Monterrey, fue de poca duración, tanto porque en el imperio español se restableció el absolutismo, como porque Joaquín Arredondo, jefe político y comandante militar de aquella región, nunca vio con agrado que su poder se diluyera entre los miembros de un cuerpo electo. ${ }^{7}$ Con la restauración del régimen cons-

7 Benson, Diputación, 1994, pp. 39-40. titucional, la Segunda Diputación Provincial de Oriente fue electa y quedó instalada a fines de $1820 .{ }^{8}$ Al terminar su gestión en diciembre de año siguiente, este cuerpo entregó sus archivos a Gaspar López, sucesor de Arredondo. Con fuerte disgusto de los regiomontanos, López trasladó los archivos de la diputación a la ciudad de Saltillo?

A inicios de 1822 se eligen los miembros de la Tercera Diputación Provincial de Oriente. En este respecto, durante el año suceden dos acontecimientos importantes. Por una parte, en los primeros tres meses Nuevo Santander inicia el proceso para separarse del resto de las provincias nororientales con el fin de establecer su propia diputación provincial, hecho que logra en el otoño. ${ }^{10}$ Por otro lado, en ese año tanto Gaspar López como el Ayuntamiento de Monterrey solicitan a la Junta Provisional Gubernativa en la ciudad de México que la diputación permanezca en Monterrey, mientras que el Ayuntamiento de Saltillo pide al mismo congreso que la junta provincial se traslade a esta ciudad. ${ }^{11}$ Los "saltilleros" (como los llamaba el padre Mier), encabezados por Miguel Ramos Arizpe, no están exentos de apoyo en la ciudad

${ }^{8}$ Francisco Bruno Barrera a los ayuntamientos de Cadereyta, Mota, China, etc., Monterrey, 10 de diciembre de 1820, en Archivo General del Estado de Nuevo León (en adelante AGENL), fondo Colonial, ramo Militar, caja 4.

?Benson, Diputación, 1994, p. 106.

10 Actas constitucionales mexicanas, 1980, vol. 2, pp. 36-37.

${ }^{11}$ Ibid., vol. 1, pp. 269, 281-289. 
de México, pues cuentan con la ayuda y prestigio de Anastasio Bustamante, nuevo comandante general de Provincias Internas. ${ }^{12}$

Estos dos acontecimientos atrasaron la aprobación de la diputación nororiental por parte del Primer Congreso Constituyente (atraso aplicado, a su conveniencia, por Gaspar López). Este legislativo decretó la existencia de esa corporación el 14 de octubre de 1822. Sin considerar a la provincia de Nuevo Santander (cuyos acontecimientos políticos siguieron su propio curso), ${ }^{13}$ se dispuso que la nueva Diputación Provincial de Oriente tuviera su asiento en la ciudad de Monterrey. Este triunfo fue el resultado de las gestiones en el Primer Congreso Constituyente de los diputados por Nuevo León fray Servando Teresa de Mier y Juan Bautista de Arizpe, quienes al parecer fueron presionados, vía sus dietas, por el Ayuntamiento de Monterrey. Una vez que quedó instalada la Junta Nacional Instituyente, el apoyo a la ciudad de Monterrey para ser el asiento de la diputación provino de Antonio de Elozúa, uno de los diputados por Coahuila (originario de Monclova) y de Refugio de la Garza, diputado por Texas.

Vale comentar aquí que las dietas de los diputados debían ser cubiertas por la Tesorería nacional; como ésta se hallaba en bancarrota, el Congreso determinó en agosto que fueran las diputaciones provinciales las que se hicie-

12 Diez cartas, 1940, pp. 27-31 (carta 9).

13 A pesar del grupo neoleonés que en los meses posteriores continuó considerando a esta provincia como parte del proyecto nororiental de gobierno. ran cargo de estos pagos. En parte por obra de Gaspar López, en las provincias nororientales no había diputación provincial instalada, por lo que al parecer fue el Ayuntamiento de Monterrey el que se hizo cargo de las dietas; no sólo de los diputados por el Nuevo Reino de León, sino también de los de Coahuila y el de Texas. A José Antonio Gutiérrez de Lara, diputado por Nuevo Santander, "nada le falta porque le envía dinero Felipe de la Garza". ${ }^{14}$

El decreto del 14 de octubre pasó al Supremo Consejo de Estado que lo aprobó y, en forma de decreto imperial con fecha 25 de febrero de 1823 , lo envió a Antonio Crespo, comandante militar interino de las Provincias Internas apostado en Monclova, quien acusó recibo el 17 de marzo siguiente. ${ }^{15} \mathrm{Al}$ parecer, el decreto imperial también tardó en llegar a la provincia de Nuevo Santander. ${ }^{16}$

${ }^{14}$ Diez cartas, 1940 , pp. 34-36 (carta 10). Sobre la ascendencia del cabildo civil regiomontano en las posiciones de los diputados del primer constituyente y junta nacional instituyente, particularmente sobre Juan Bautista de Arizpe, véase Actas de Cabildo en el Archivo del Ayuntamiento de Monterrey (en adelante AAM), v. 999, acta 08/1822, 18 de noviembre de 1822 .

is José Ignacio García Illueca a los secretarios del Congreso (restituido), México, 11 de abril de 1823; Antonio Crespo a José Ignacio García Illueca, Monclova, 17 de marzo de 1823 en Archivo General de la Nación (en adelante AGN), Gobernación, sin sección, 1823, caja 45, exp. 11, fs. 1-7.

16 Véase al respecto Juan Echandía a la Junta Provisional Gubernativa en Monterrey, Aguayo, 13 de marzo de 1823 en AGENL, ramo Adhesión de las Provincias Internas de Oriente al Plan de Casa Mata (en adelante APCM), 1823, caja 1, exp. 19. 
El artículo 9 del plan de Casa Mata señala: ${ }^{17}$

En el ínterin contesta el supremo gobierno de lo acordado por el ejército, la Diputación Provincial de esta provincia [Veracruz] será la que delibere en la parte administrativa si aquella resolución fuese de acuerdo con su opinión.

Lo que en resumidas cuentas implicaba este artículo era que cada diputación provincial que se adhiriera a este plan asumía el control administrativo de su provincia: en la época, esto significaba el gobierno en lo político y en lo económico. ${ }^{18}$

Hacia finales de febrero de 1823 llegó a Monterrey noticia del plan proclamado en Casa Mata el primer día de ese mes. El 6 de marzo se votó la adhesión al plan y se acordó establecer en esa ciudad una junta provisional gubernativa para las cuatro provincias, incluida la de Nuevo Santander. ${ }^{19}$ El objeto de esta junta provisional era

reasumir facultades vastas y amplísimas [...] sustrayéndose [a] la obediencia del

17 Jiménez, Planes, 1987, pp. 143-144.

${ }^{18}$ Benson, Diputación, 1945, p. 52.

19 Véase Benson, Diputación, 1994, pp. 130 131. La inclusión de Nuevo Santander responde a que, dada la influencia del padre Mier sobre las autoridades regiomontanas, en Monterrey no se reconocía la soberanía de esta provincia. Diez cartas, 1940, p. 14 (carta 4). Por otro lado, para inicios de marzo de 1823, en Nuevo Santander no se conocía el decreto que les otorgaba la categoría de diputación provincial. Juan Echandía a la Junta Provisional en Monterrey, Aguayo, 13 de marzo de 1823 en AGENL, ramo APCM, 1823, caja 1, exp. 19. gobierno [...por no haber] un centro de unión nacional, [por lo que] era preciso obrar con independencia absoluta mientras llegaba el caso de que no se instalase un gobierno provisional. ${ }^{20}$

Dado que existía un decreto, aprobado por el congreso disuelto, que autorizaba la instalación de la Diputación Provincial de Oriente, lógico es pensar que quedara instalada esta corporación (y no una junta provisional) inmediatamente después de que se votó la adhesión al plan de Casa Mata. No fue así, pues en su lugar se establecieron juntas provisionales gubernativas en Monterrey, Monclova y Saltillo. La razón de esta "medida de transición", señala Miguel Ramos Arizpe, fue el respeto que se tuvo hacia las otras provincias de determinar su adhesión al plan militar y su deseo de formar parte de una junta general. ${ }^{21}$

Poco más de tres semanas después, el 31 de marzo, quedó instalada en Monterrey la Diputación Provincial de Nuevo León, Coahuila y Texas que sustituyó a la Junta Provisional Gubernativa regiomontana formada a inicios del mes. Según documentos de la época, este cuerpo se estableció a instancias del Ayuntamiento de Monterrey, el cual cinco días antes había presentado un Plan de Proposiciones para Organizar el Gobierno de las Provin-

${ }^{20}$ La Diputación Provincial en Monterrey a José Ignacio García Illueca, Monterrey, 25 de abril de 1823 en AGN, Gobernación, sin sección, caja 43, fs. 196-198.

21 Acta de la Junta Provisional Gubernativa, Monterrey, 31 de marzo de 1823 en AGN, Gobernación, sin sección, caja 43, exp. 9, fs. 182-185. 
SECUENCIG

oculto nuertion rostro para descubir

has en la complicidad que

acle lo que no querem os vere L mundo enmarcado en una visio

" pequetal que nada ve todo y no tod - pos eso mismo encarillado en el hueco de un solo cereno la exittencia reducida a la sale el comedor el buts y la teluisión a falras cobras ciomo de ve el munds desde la cerce scoure de regra lana d caler. que topa las orejios lai dentificraiont con to clos los clemán en capuchados que ton

pocosy muchus a havere $l$ dscarate rmascaradar la us da encarcelach pen woonden maer rey/s siet in inkt geen worden geen daden par alisads el qulhacer de la videla la humamid ad derenmascarada trittion di alma en una selve de atrocidades cotidianar y fromiluxs que desaymona in sanboras omniprente

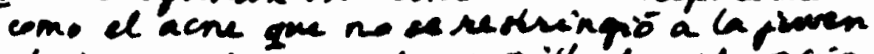
tha cuantar oricibmes rilladas at incio del no decit palebra cadenas de actos six comizuzo suppeachidos en la onda sonora que nos acomparia Uena el silencio dal hembre resulta mai clocuente sur lad

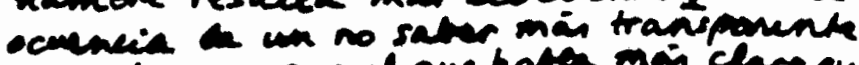
Q que duence que de que have main claro que

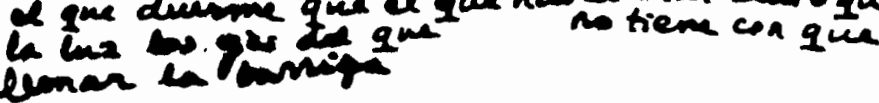


cias. ${ }^{22}$ Aunque la sesión de instalación de la junta no lo indica, es probable que este plan sea el acta del 17 de marzo enviada por la Diputación de San Luis Potosí al Cabildo regiomontano. ${ }^{23}$ Ésta comunicaba la propuesta de la Diputación poblana sobre el establecimiento de un gobierno central general y en apoyo al Congreso General. ${ }^{24}$ Esta comunicación buscaba la formación de una Junta Central que además de que se encargara de formar un nuevo legislativo evitara la anarquía que amenazaba a la nación mexicana. ${ }^{25}$

En la junta del 31 de marzo el Ayuntamiento de Monterrey propuso que la Diputación Provincial recién instalada procediera inmediatamente a la desig-

22 AAM, vol. 999, acta, 15/1823, 25 de marzo de 1823.

23 Acta de la Junta Provisional Gubernativa, Monterrey, 31 de marzo de 1823 en AGN, Gobernación, sin sección, caja 43, exp. 9, fs. 182-185. Barragán señala que la instalación de la Diputación nororiental se originó de una orden del Congreso restaurado iniciada por el padre Mier. Sin embargo, la iniciativa del clérigo tegiomontano y las discusiones en el Congreso se dieron en los primeros días de abril: después de que se consumaron los hechos en las provincias. Esto quizá revele que Mier esperó a que quedara establecido el Supremo Poder Ejecutivo; quizá muestra que Ramos Arizpe (presidente de la nueva diputación) se le adelantó. En cualquier caso me parece que queda en evidencia que el Ayuntamiento de Monterrey se tomó muy en serio el ejercicio de su soberanía al disolver a la junta y convocar a la $\mathrm{Di}$ putación.

${ }^{24}$ Alamán, Historia, 1985, vol. 5, pp. 717-718.

25 "La [Diputación Provincial] de Puebla [...] ya para el día 4 de marzo había enviado a las diputaciones provinciales y ayuntamientos de todo México comunicaciones en las que les proponía que enviatan representantes a Puebla con el obje- nación de los dos diputados que irían a Puebla.26 En segundo lugar, señaló la necesidad de que se reunieran los diputados de las cuatro provincias (Nuevo León, Coahuila, Texas y Nuevo Santander). Por último, el Cabildo civil sugirió que los representantes de estas mismas se reunieran antes de acudir a Puebla con el fin de "acordar lo conveniente a dichas provincias". 27

Miguel Ramos Arizpe, presidente de la Tercera Diputación Provincial, ${ }^{28}$ estuvo en lo general de acuerdo con los postulados del Cabildo regiomontano. La junta de Puebla, y las instrucciones

to de conferenciar sobre el problema de constituir un gobierno nacional provisional y también sobre el restablecimiento del antiguo Congreso o la convocación de uno nuevo." Benson, Diputación, 1994, p. 138.

26 El protagonismo del Ayuntamiento de Monterrey viene de que fue el primero en adherirse al Plan de Casa Mata (probablemente porque fue el primero que lo recibió), fue el encargado de distribuirlo en las cuatro provincias y dio su "aval" a la instalación de la junta, mismo que, en cinco días, fue ratificado por el resto de los ayuntamientos de la provincia del Nuevo Reino de León. Asimismo, fue el Ayuntamiento de Monterrey el que le agregó dos artículos al plan veracruzano: el más importante de éstos fue que se convocara a un nuevo congreso. Véanse las adhesiones de los municipios y la Acta del Cabildo de Saltillo y otros individuos, Saltillo, 7 de marzo de 1823 en AGENL, ramo APCM, 1823, caja 1, exps. 57 , 15 y 16 .

27 Acta de la Junta Provisional Gubernativa, Monterrey, 31 de marzo de 1823 en AGN, Gobernación, sin sección, caja 43, exp. 9, fs. 182-185.

28 La Diputación Provincial reunida en Monterrey el 31 de marzo de 1823 estuvo formada por los diputados electos a inicios de 1822: Miguel Ramos Arizpe, José Bernardino Cantú, José de León Lobo, José Vivero, Julián de Arrese, José 
que enviaría la Diputación nororiental eran de fundamental importancia para el futuro de la nueva nación, pues allí se decidiría si se reconocía al Congreso restaurado el 7 de marzo.

El primer día de abril se nombraron a los dos representantes para la reunión de Puebla: Melchor Múzquiz y Servando Teresa de Mier. Las instrucciones que recibieron por parte de la junta regiomontana fueron las de que votaran por la convocatoria a un nuevo congreso y por el establecimiento de un gobierno central provisional. Tanto la designación como las instrucciones, empero, resultaban un tanto inoportunas, toda vez que los dos representantes ya habían asistido a las juntas poblanas (de hecho, Benson señala que éstas terminaron hacia mediados de marzo). ${ }^{29}$ La presencia de Múzquiz y Mier, sin haber sido designados ex profeso como representantes de

Antonio Rodríguez, Francisco Eusebio de Arizpe, brigadier Juan Nepomuceno de la Peña, José María Parás y Rafael del Llano. Acta de la Junta Provisional Gubernativa, Monterrey, 31 de marzo de 1823 en AGN, Gobernación, sin sección, caja 43, exp. 9, fs. 182-185.

29 Benson, Diputación, 1994, pp. 146-148. El 1 de abril la diputación ordenó al tesorero en Saltillo que enviara las dietas a Mier y Múzquiz (este es el documento que, según Benson, tiene acotaciones de Ramos Arizpe). Borrador de manuscrito sin firma dirigido al tesorero de las cajas nacionales de Saltillo en AGENL, ramo APCM, Monterrey, 1 de abril de 1823. Lo "inoportuno" de la designación de estos dos individuos pudo deberse a que la nueva diputación tenía que oficializar su presencia en Puebla, por lo que, aunque ya hubieran terminado las reuniones, se debía hacer la designación como un ejercicio de soberanía y autodeterminación. Otra razón sugerente sería que las provincias norientales, obedeció a que en las reuniones de Puebla asistió un grupo de diputados miembros del Congreso restituido: Mier era diputado propietario por Nuevo León; Múzquiz por el Estado de México.

Este hecho les permitió participar en el rejuego político de aquellos días. Melchor Múzquiz, al parecer en su calidad de representante de la Diputación nororiental; secundó la propuesta de Valentín Gómez Farías de que se reconociera provisionalmente al Congreso hasta que se pudiese convocar uno nuevo. ${ }^{30}$ En Monterrey, entretanto, se reunía la Diputación Provincial para discutir las instrucciones dadas a los comisionados. Ramos Arizpe señaló que aunque el reconocimiento del Congreso restaurado era contrario a dichas instrucciones, convenía la aprobación que hiciera Múzquiz, siempre y cuando el Congreso se hiciera cargo de convocar a un nuevo legislativo. Se sometió a votación por parte de los diputados y se acordó reconocer a este cuerpo y al Supremo Poder Ejecutivo. ${ }^{31}$

La Diputación Provincial asentada en Monterrey se instaló con los deseos del Ayuntamiento de esta ciudad de reunir a las cuatro provincias de oriente. Sin embargo, sólo se reunió la de Nuevo León, con tres representantes, y las de Coahuila y Texas con un representante cada una. En la realidad, la

Ramos Arizpe necesitaba el apoyo de las juntas de Monclova y Saltillo para el establecimiento de la diputación provincial, por lo que la "urgencia" para nombrar a los representantes era una forma de presión a estas juntas.

${ }^{30}$ Benson, Diputación, 1994, pp. 151-152.

${ }^{31}$ Ibid., 1994, pp. 154-155. 
Diputación debía de estar formada por dos representantes de Nuévo León, dos de Coahuila y uno de Texas. ${ }^{32}$ Cada una de las provincias que componía la Diputación Provincial tuvo sus razones para que ésta quedara incompleta. En el caso de Nuevo Santander, no se lo consideró para la formación de una Diputación Provincial de Oriente porque se hallaba en proceso de establecer un cuerpo análogo con asiento en la Villa de San Carlos. En el caso de Coahuila, su ausencia en la Diputación reunida en Monterrey obedeció a que la Junta de Saltillo se opuso por unanimidad a enviar representante "por no reconocer[le a la Junta de Monterrey] en ningún caso autoridad, ni superioridad alguna"; asimismo, el cuerpo saltillense instó a que el distrito de Parras tampoco enviara representante a la Junta. ${ }^{33}$

La ausencia de los representantes de Saltillo de la Diputación Provincial establecida en Monterrey resultaba importante no sólo porque tanto el parti-

32. Quedaba por resolver qué hacer con los dos diputados restantes de los siete que debían formar el cuerpo provincial. El hecho de que Nuevo León tuviera tres representantes, y el deseo, expresado en la carta al ministro del Interior en la que se le comunicaba la instalación de la junta, sugiere que este problema se arreglaría con un diputado adicional para cada una de las dos provincias restantes. La Diputación Provincial en Monterrey a José Ignacio García Illueca, Monterrey, 16 de abril de 1823 , en AGN, Gobernación, sin sección, caja 43, exp. 9, fs. 180-182.

${ }^{33}$ José Ignacio Sánchez Navarro a los presidentes y vocales de la Junta Provisional Gubernativa, Saltillo, 26 de marzo de 1823; Agustín Viesca a los presidentes y vocales de la Junta Gubernativa de Monterrey, Parras, 5 de abril de 1823 en $A G N$, Gobernación, sin sección, caja 43, fs. do de aquella villa como el de Parras debían estar presentes para formar una verdadera diputación regional, sino porque resultaba difícil que operara la Diputación. Y es que Gaspar López, comandante general de las cuatro provincias, no reconocía la autoridad de ninguna junta, no obstante que, a regañadientes, había aceptado el Plan de Casa Mata. El resultado de esto es que López, al ver que perdía el poder conferido por las autoridades de la ciudad de México, luchó en contra de la Junta Provisional de Monterrey, y cuando fue derrotado debió salir de la provincia. Sin embargo, el archivo de la comandancia (que contenía todos los documentos del gobierno de las Provincias de Oriente) se quedó en Saltillo, por lo que la Diputación Provincial regiomontana se vio incapacitada para realizar cabalmente su trabajo. Y aún más: toda la correspondencia que anteriormente se enviaba a la comandancia general se detenía en Saltillo; por ello, la Diputación instó al administrador de Correos saltillense a que le hiciera llegar la correspondencia de dicha comandancia. Al respecto, este funcionario responde a la Diputación que no obedece el oficio que le envía pues la "Junta de Monterrey que se dice Diputación Provincial [...] se dirige a hacer reconocer una autoridad que no tiene". ${ }^{34}$

186 y 188. Por otro lado, y "por miras puramente locales", Saltillo ni siquiera reconocía a la junta de Monclova. Véase La Diputación Provincial en Monterrey a José Ignacio García Illueca, Monterrey, 16 de abril de 1823 en AGN, Gobernación, sin sección, caja 43, exp. 9, fs. 180-182.

31 Jesús María de la Garza a la Diputación Provincial en Monterrey, Saltillo, 5 de abril de 1823 en AGN, Gobernación, sin sección, caja 43, s/f. 
En cierto sentido, el argumento del administrador de correos de Saltillo para no obedecer a la "Junta de Monterrey", mismo que por cierto copiaba los argumentos del Ayuntamiento de aquella villa coahuilense, no carecía de fundamento. La corporación saltillense decía que la Diputación Provincial instalada en la capital neoleonesa debió elegir nuevos diputados y no sólo renombrar a los que ya existían (los que habían sido electos en enero de 1822). Esto significaba que la Diputación regiomontana obedecía el decreto del 24 de octubre anterior que estipulaba que se instalaría una diputación en Monterrey "con los individuos que de antemano estaban nombrados". La posición de las autoridades saltillenses estaba acorde con la idea proveniente de la legislación gaditana que decia que si faltaba la autoridad superior, el poder pasaba a manos de los ayuntamientos; 35 por tanto, ya que dichas autoridades se hallaban separadas del gobierno de México, no existía razón alguna para reconocer el poder de una diputación formada a la sombra de un decreto promulgado en los meses del imperio iturbidista.

A pesar de que contaban con la presencia de un representante ante la $\mathrm{Di}$ putación Provincial en Monterrey, las autoridades texanas en realidad no se consideraban parte de esta corporación. Por supuesto, tal afirmación se debe matizar, pues parece que la población

${ }^{35} \mathrm{El}$ argumento se apoya en el artículo $10 \mathrm{del}$ capítulo tercero de las "Instrucción para los ayuntamientos constitucionales, juntas provinciales y jefes politicos superiores" en Hernández y Dávalos, Historia, 1985, vol. 5, p. 579. en general y la tropa de hecho deseaban adherirse al "sistema de la verdadera libertad". De cualquier forma, desde que se supo la promulgación del Plan de Casa Mata las autoridades en Texas se opusieron a la abdicación de Iturbide. ${ }^{36}$ La razón de esto se explica por la conducta de Félix Trespalacios, gobernador de aquella región, quien se había unido a los jefes de las tribus bárbaras, específicamente los comanches, para que sostuvieran el sistema anterior aduciendo que "si no mandaba el emperador Iturbide no [...] daban la paz, y si antes habían hostilizado estas provincias, ahora lo harían con más empeño". El comportamiento de Trespalacios fue motivo para que a mediados de abril Pedro Lemus, comandante de armas de Nuevo León, emprendiera una investigación en contra de Trespalacios; ésta reveló la connivencia del gobernador tejano con los jefes de comanches, zacagues, lipanes y zacuanos. ${ }^{37}$

Como resultado de esta investigación, Lemus exigió apoyos a la Diputación Provincial en Monterrey con el fin de iniciar una expedicion punitiva en contra de Trespalacios. Por dos razones, la Diputación le negó a Lemus los recursos solicitados: por una parte, porque no contaba con las posibili-

36 Benson, Diputación, 1994, p. 133. Pedro Lemus al marqués de Vivanco, general en jefe del ejército libertador, Monterrey, 13 de abril de 1823, AGN, Gobernación, sin sección, caja 43, exp. 9 , f. 63 .

37 Declaración de Ramón Sánchez, Monterrey, 15 de abril de 1823, y Declaración de José Antonio de la Garza, Monterrey, 21 de abril de 1823 en AGN, Gobernación, sin sección, caja 43, s/f. 
dades de juntar entre 400 y 500 hombres y 10000 pesos en reales, que era a lo que ascendía lo exigido por Lemus; por otro lado, en un acto de suma cautela política por parte de la Diputación, este cuerpo decidió tomar en consideración los resultados de la investigación y adoptar medidas de precaución "hasta que intentando el medio de la persuasión y mandando mejores datos y conocimientos no se satisficiese de la inutilidad de ellas". Según reporte del Ayuntamiento de Monterrey que a inicios de mayo enviara a Felipe de la Garza, nombrado comandante general de las cuatro provincias nororientales desde el anterior 17 de marzo y en sustitución de Gaspar López, ${ }^{38}$ la negativa de la Diputación provocó la ira de Lemus, quien entre insultos a esta corporación, mandó comisionados a recoger soldados de toda la provincia. Esto en sí no era grave, desobedecer a la Diputación sí lo era; y más aún si, como señalaba el Ayuntamiento regiomontano,

había un plan que estaba combinando con Miguel Ramos Arizpe sobre jurar la república y separar estas provincias de México después de [haber] prestado el reconocimiento debido al soberano Congreso y al Supremo Poder Ejecutivo.

En vista de que Lemus logró sacar a la guarnición de la ciudad, y de que una parte de ésta desconocía la autoridad de la Diputación Provincial, las autoridades de la ciudad de Monterrey se vieron obligadas a echar mano de la

${ }^{38}$ Alessio Robies, Coabuila, 1940-1946, vol. 1, p. 151 . milicia cívica, la cual logró la rendición de los rebeldes, en parte gracias al apoyo del supremo gobierno por la vía de Felipe de la Garza y de Mariano Laris -a la sazón comandante general de Zacatecas-, quien ofreció "todo el caudal necesario para que la empresa termine pronto", y a la amenaza de un avance sobre el traidor desde San Luis por parte de Santa Anna. ${ }^{39}$ Pedro Lemus fue conducido a San Luis Potosí y de ahí a la ciudad de México para que se le formara juicio sumario. ${ }^{40}$

La supuesta cooperacion entre Lemus y Ramos Arizpe sugiere el deseo de ambos de que las provincias de oriente se declararan por un sistema federal. Al respecto, sin duda refiriéndose a estos dos personajes, Carlos María de Bustamante asienta en su diario el 21 de abril de 1823:

En Monterrey se ha formado una junta con miembros de Coahuila, Texas, Santander, etc. Estas cuatro provincias indican separarse y aspirar a una federación con México $[\ldots]$ sobre ello trabajan sin cesar los iturbidistas y frailes. ${ }^{41}$

39) José Ignacio García Illueca a la Diputación Provincial en Monterrey, México, 28 de abril de 1823 en AGENL, Correspondencia, Ministerio de Guerra y Marina, caja 1.

40 El Ayuntamiento de Monterrey a Lucas Alamán, ministro de Estado y de Relaciones Interiores y Exteriores, Monterrey, 9 de mayo de 1823 en AGN, Gobernación, sin sección, caja 43, exp. 9, fs. 268-270.

41 Bustamante, 1980, Diario, tomo 1, vol. I, p. 223. Benson señala que Ramos Arizpe hablatba de una república federada desde "mucho antes de marzo de 1823"; así lo señalan, según ella, los documentos de la Diputación Provincial, del. Ayuntamiento de Monterrey, del padre Mier, y la 
La junta a la que se refiere Bustamante sin duda es la que formó Miguel Ramos Arizpe el 10 de abril en Saltillo. El primer objeto de ésta era unificar los criterios con la Diputación regiomontana y eventualmente desplazar a la Junta saltillense a la ciudad de Monterrey.

Sobre el asunto de Texas, tal parece que la formación de la junta formada en Saltillo por Miguel Ramos Arizpe fue motivo para que Félix Trespalacios se acercara a este personaje con una actitud conciliadora. ${ }^{42}$ Esto probablemente explique por qué, en los primeros días de mayo, Trespalacios se desplazó a la villa de Laredo, un hecho que fue interpretado por Felipe de la Garza como una amenaza sobre la guarnición militar de Punta de Lampazos; ${ }^{43}$ difícilmente, pues según la investigación que previamente hiciera Pedro Lemus, Trespalacios contaba cuando mucho con 750 hombres, la mayoría pertenecientes a las llamadas tribus bárbaras. En todo caso, De la Garza solicitó al Supremo Poder Ejecutivo que se le proporcionaran hombres y dineros para la expedición en contra de Texas. ${ }^{44}$ El re-

correspondencia que a partir de mayo de 1823 sostuvieron Ramos Arizpe y Esteban Austin. Benson, Diputación, 1994, p. 192n. La afirmación de "iturbidistas y frailes" de Bustamante se refiere al grupo de Ramos Arizpe. Lemus, "Parte", 1823.

42 José Félix Trespalacios a Miguel Ramos Arizpe, Béjar, 24 de abril de 1823 en AGN, Gobernación, sin sección, caja 43, exp. 9, f. 70 .

43 Vicente Arreola a la Diputación Provincial en Monterrey, Punta de Lampazos, 7 de mayo de 1823 en AGN, Gobernación, sin sección, caja 43 , exp. 9, f. 69.

${ }^{44}$ Felipe de la Garza a Lucas Alamán, Soto la Marina, 10 de mayo de 1823 , en AGN, Goberna- sultado de esto fue que, sin registrarse hechos de armas, Trespalacios aceptó la situación que vivía el resto del país, mientras que la Junta de Texas, que desde mediados de abril se había pronunciado por el Plan de Casa Mata, ${ }^{45}$ se adhería a la Diputación Provincial establecida en Monterrey. ${ }^{46}$ Para finales de mayo De la Garza marchaba sobre la capital de la provincia de Texas con el objeto de imponer un nuevo gobernador. ${ }^{47}$

ción, sin sección, caja 43, exp. 9, fs. 71-72. De la Garza se hallaba en Soto la Marina con el objeto de unirse a la expedición que Santa Anna emprendiera en contra de los sublevados en Nuevo Santander y en Texas. Ya para la fecha de esta carta, empero, Santa Anna se dirigía al centro del país. Benson, Diputación, 1994, p. 164. De la Garza, por su parte, se dirigió a Monterrey, "sin esperar el resultado de la expedición del general Santa Anna [y] sin impetrar [su] auxilio [...] porque teniendo pleno conocimiento de la calidad y número de tropas de estas provincias, necesito únicamente que $\mathrm{S}$. A. provea de numerario para equipo y mantenimiento de $700 \mathrm{u} 800$ hombres que creo suficientes para imponer al golbernador de Texas el respeto al soberano Congreso Nacional y a su legítimo gobierno."

45 Benson, Diputación, 1994, p. 133.

${ }^{46} \mathrm{La}$ junta de Texas a la diputación provincial de Monterrey, Béjar, 30 de abril y 3 de mayo de 1823; La Diputación Provincial de Nuevo León, Coahuila y Texas a Lucas Alamán, Monterrey, 16 de mayo de 1823; Felipe de la Garza a Lucas Alamán, Monterrey, 30 de mayo de 1823 en AGN, Gobernación, sin sección, caja 13 , exp. 9, fs. 263-266.

47 La Diputación Provincial en Monterrey a Lucas Alamán, Monterrey, 9 de mayo de 1823 en AGN, Gobernación, sin sección, caja 43, exp. 9, f. 264 [Sobre los movimientos de De la Garza, véase la nota al margen escrita después del 22 de mayo]. 
EL ESTABLECIMIENTO DEL FEDERALISMO EN NUEVO LEÓN

Según Nettie Lee Benson, para más o menos mediados de marzo de 1823 casi todas las provincias que posteriormente formarían la república mexicana se habían adherido al Plan de Casa Mata. En el caso de Nuevo León, la adhesión y la posterior formación de la Diputacion Provincial, asentada en Monterrey, significó la asunción de sus propios asuntos, así como la independencia con respecto al gobierno iturbidista. Aun así, empero, en abril de 1823 no se percibe el deseo de una separación definitiva de las provincias nororientales del resto de la nación. De hecho, no existía la posibilidad, pues en el caso de Nuevo León-CoahuilaTexas y de Nuevo Santander las diputaciones provinciales se habían formado con los mismos miembros de antes de que se promulgara el Plan de Casa Mata, con lo que ciertamente se aseguraba una forma de unión de las provincias con el centro. 48

La idea de que las diputaciones provinciales nororientales se formaran de los mismos representantes de antes fue del padre Mier, quien deseaba contar con adeptos en la Diputación neoleonesa. $Y$ es que en esos momentos en

48 Véase al respecto el decreto del soberano Congreso Constituyente del 22 de abril de 1823, que señala: "que se instale en Monterrey una diputación provincial, compuesta de las tres provincias de Nuevo Reino de León, Coahuila y Texas [...] sus individuos serán los que anteriormente estaban elegidos". Decreto del Soberano Congreso Constituyente, México, 22 de abril de 1823 en AGN, Gobernación, sin sección, caja 53, exp. 7. los que no se tenía una idea muy clara de qué era lo mejor para el país, el clérigo regiomontano tenía la idea de que una forma de gobierno central funcionaría por un lapso de más o menos diez o doce años. La razón de esta posición la comunicaba Mier al Ayuntamiento de Monterrey el 2 de abril al señalar que "no hay en las provincias elementos necesarios para ser cada uno estados soberanos [por lo que] todo se volvería disputas y divisiones". ${ }^{49}$ Fray Servando buscó imponer en las provincias nororientales su propia posición centralista -característica de la primavera de $1823-50$ al enviar a su primo Felipe

19 Véase la carta del 2 de abril de 1823, en Diez cartas, 1940, p. 5 (carta 1).

50 Según la terminología de Torcuato di Tella, Mier formaba parte del grupo de "liberales moderados" que, "en abril de 1823 , recién reunido el Congreso, decidió que no era necesario elegir nuevos representantes hasta que hubiese transcurrido el periodo legal de los anteriores lal final del año]". Di Tella, Política, 1994, p. 163. Esta posición se hace evidente en el dictamen que la comisión de Gobernación hiciera sobre el decreto del 14 de octubre de 1822 que señalaba que los dipurados provinciales de Nuevo León/Coahuila/ Texas y Nuevo Santander serían renovados. En este dictamen, la comisión señalaba que este decreto era "equívoco por defecto de redacción exacta" y que en realidad se buscaba que estas diputaciones fueran compuestas por los individuos ya nombrados. Por cierto, el dictamen de la comisión se originó de una propuesta que pocos días antes hiciera fray Servando, lo que muestra que el estilo presuntuoso de sus cartas tenía ciertos fundamentos. Fray Servando Teresa de Mier al Congreso General, 2 de abril de 1823; Dictamen de la comisión de Gobernación sobre la petición de Mier, México, 9 de abril de 1823 en AGN, Gobernación, sin sección, caja 45, exp. 11. Al respecto, véase también la carta del 23 de abril de 1823 , en Diez cartas, 1940, p. 9 (carta 3). 
de la Garza para que se hiciera cargo de la comandancia general de aquella región. ${ }^{51}$

Los planes de Mier (y del Congreso general) para la provincia de Nuevo León, Coahuila y Texas se vieron obstaculizados por Miguel Ramos Arizpe, quien renunció a la presidencia de la Diputación el 1 de abril de 1823 para formar una junta que, según el Cabildo regiomontano, tenía aspiraciones separatistas. En realidad, la junta formada por Ramos Arizpe buscaba que se formara una diputación compuesta de las cuațro provincias (Nuevo León, Coahuila, Texas y Nuevo Santander), misma que sólo obedecería al Congreso general y no al poder ejecutivo, situación que sugería la formación de una provincia confederada. 52

El 23 de abril, Mier comunicó al Ayuntamiento de Monterrey que había recibido un escrito, proveniente de

S1 Véase carta del 9 de abril de 1823, en Diez cartas, 1940 , p. 8 (carta 2). Por otro lado, fray Servando envió a Felipe de la Garza al norte con el objeto de evitar que Miguel Ramos Arizpe se llevara la diputación provincial a Saltillo. Esto no sólo lo hacía por razones políticas sino personales; a Mier le convenía que la diputación se hallara en Monterrey porque de esa manera, siendo él representante de Nuevo León, se le enviaría su dieta con regularidad, de la misma manera como el diputado Elosúa recibía la suya de la Tesorería saltillense. $\mathrm{Al}$ respecto, véase también carta del 23 de abril de 1823, en Diez cartas, 1940, pp. 10-11 (carta 3).

52 Ramos Arizpe estaba convencido de que la provincia debía comprender las cuatro regiones, porque de esa manera tendría los recursos para poder hacer oír su voz en el Congreso y ante el ejecutivo y sus empleados. Ramos, "Informe", 1989, pp. 77-78. esa ciudad o de Saltillo, sobre la propuesta de formar una sola provincia confederada. Este documento, que al parecer contenía las ideas de Ramos Arizpe, Mier lo presentó al Congreso y al Supremo Poder Ejecuctivo, y en ambos casos fue aceptado. ${ }^{53} \mathrm{Y}$ a pesar de que no se formó la Diputación compuesta de cuatro provincias, dicha aprobación muestra que las autoridades generales, quizá forzadas por las circunstancias, aceptaron la posibilidad de que la región nororiental de México se declarara parte de una confederación.

Por su parte, y consistente con la idea de una sola diputación ampliada, Ramos Arizpe hacía esfuerzos por unificar las opiniones de los distritos de Monterrey y Monclova con las de Saltillo. ${ }^{54}$ Las juntas que con este propósito se realizaron en esta última localidad dieron pie para que a finales de mayo, reunidas las autoridades y vecinos del distrito, Saltillo se pronunciara, entre otras cosas, por una república federal, la formación de un estado que comprendiera las cuatro provincias de la diputación previamente propuesta y por la independencia de éste en materia de gobierno y economía interna. A inicios de junio, en una reunión similar, se acordó que el gobernador del estado sería Felipe de la Garza, quien convocaría un congreso estatal encar-

53 Diez cartas, 1940, p. 9 (carta 3). Para la presentación de este proyecto ante el Congreso véase Barragán, Introducción, 1994, pp. 142-143.

${ }^{54}$ De las empresas de Ramos Arizpe en mayo de 1823 fue testigo Esteban Austin quien, de visita en Saltillo, dejó testimonio de estos hechos en su correspondencia. Al respecto, véase Benson, Diputación, 1994, pp. 192, 194. 
gado de elaborar la Constitución local. 55

Felipe de la Garza no fue la cuña que el padre Mier esperaba poner a Ramos Arizpe, fundamentalmente porque aquél se unió a éste para realizar sus ideas. ${ }^{56}$ En esta colaboración participó el Ayuntamiento de Saltillo. De la Garza llegó a Monterrey el 24 de mayo e inmediatamente escribió al Ayuntamiento de Saltillo para que le explicara las razones de su separación de la Diputación regiomontana; el Cabildo saltillense le respondió que des-

5s Es probable que la segunda reunión en Saltillo (4 de junio) fuera la respuesta al decreto del Congreso restaurado del 21 de mayo anterior, toda vez que los correos desde la ciudad de México tardaban entre seis y siete días. Este decreto convocaba a un nuevo congreso y sugería al gobierno que "conforme a las leyes en vigor, sometiera a las autoridades y diputaciones provinciales, que se habían estado separando de la senda trazada por la Constitución, en los términos de su deber, usando de preferencia los medios de persuasión y lenidad". Es por esta última disposición por la que la primera resolución de la segunda junta de Saltillo fuera precisamente el reconocimiento al supremo poder ejecutivo y al Congreso restaurado, "como un cuerpo destinado a expedir la convocatoria de la nueva asamblea deliberante que se encargará de preparar la constitución general del país. Barragán Barragán, Introducción, 1994, pp. 174-175, y Benson, Diputación, 1994, pp. 195196. Las ideas emanadas de las reuniones de Saltillo son similares a las que en mayo anterior publicara el estado de Jalisco. Para la totalidad de propuestas de las juntas de Saltillo, véase Benson, Diputación, 1994, pp. 195-196. Para las ideas de jalisciences véase el Manifiesto publicado por Luis Quintanar, jefe político de aquel estado, el 21 de junio de 1823. Un análisis del documento en $\mathrm{Ba}$ rragán Barragán, Introducción, 1994, pp. 147-163. ${ }^{56}$ Benson, Diputación, 1994, p. 196n. de inicios de marzo había aceptado prácticamente todo lo que le había sugerido la comisión enviada desde Monterrey (no obstante que se sentía con todo derecho, de acuerdo con el decreto de 23 de junio de 1813 , a ostentar la cabeza de la Diputación) por el sencillo hecho de que deseaba que las cuatro provincias estuvieran unidas "para con mano fuerte coadyuvar a afirmar la independencia y libertad nacional, y a tener una parte justamente igual en la formación de la Constitución general del Estado". Sin embargo, justo cuando se esperaba la formación de la Junta General, el Ayuntamiento saltillense se enteró que ésta se había instalado sin siquiera avisarle, según esto amparado bajo el decreto del 14 de octubre de 1822. Y es que, señalaba el Cabildo saltillense, no se puede formar una junta semejante sin el consentimiento del pueblo, y la de Monterrey se estableció por un decreto de un gobierno que desde la adopción del Plan de Casa Mata había sido desconocido por aquellas provincias; 57 y lo que es peor, por

57 Al respecto, el Ayuntamiento de Saltillo señalaba a De la Garza: "Monterrey en la noche del 6 de marzo, adoptando el plan de Casa Mata, cortó toda relación con el gobierno imperial, lo mismo que todas las provincias y en la acta de aquella noche estableció una junta gubernativa cuya duración reservó exclusivamente a la decisión de un nuevo congreso general. ¿Cómo pues el Saltillo había de mirar en fines de marzo con un acto legal el obedecimiento de un decreto que destruía el princpio elemental de una eterna separación del imperio y del emperador y que además descruye [a] la junta de Monterrey y aun las esperanzas de una junta general? El Saltillo, que se daría por ofendido si alguien le llamase inconsecuente en sus principios, mira con sen- 
un decreto que se había elaborado con el solo propósito de no esparcir la asonada que el mismo De la Garza había iniciado en Nuevo Santander a principios de septiembre de 1822, un decreto que además no se dio a conocer inmediatamente después de que pasó al ejecutivo -cuando se vio que la rebelión de De la Garza no generó adhesiones- sino que se detuvo y reemitió, supuestamente mejor redactado, por la Junta Nacional Instituyente el 25 de febrero de 1823 y posteriormente, a inicios del mes de abril en el Congreso Constituyente restaurado, por el padre Mier (este último hecho le dio una supuesta legitimidad a la existencia de la junta regiomontana). $\mathrm{Y}$ aun así, continuaba el Ayuntamiento de Saltillo, el establecimiento de una diputación provincial que uniera a las cuatro provincias implicaba que todos los pueblos deseaban ser gobernados por tal cuerpo, un aspecto que el partido de Saltillo consideraba importante pues no estaba dispuesto a sujetarse a la voluntad de la Diputación regiomontana. Y a pesar de todas las diferencias, Saltillo reconoce que no puede ir contra la corriente, y le informa a De la Garza que admite a la Diputación instalada en Monterrey con los mismos miembros que tenía en enero de 1822,58 "a fin de no poner óbice por ahora a la unión justa de las cuatro provincias".

timiento la necesidad en que se le pone de notar: la inconsecuencia de otros." El Ayuntamiento de Saltillo a Felipe de la Garza, Saltillo, 1 de junio de 1823 en AGN, Gobernación, sin sección, caja 43, exp. 9, fs. 255-262.

s8 Benson, Diputación, 1994, pp. 95-96; $105-106$.
Con la unión temporal de las cuatro provincias bajo el mando de Felipe de la Garza (y en cierto sentido indirecto Nuevo León, Coahuila y Texas también bajo el mando de la Diputación Provincial instalada en Monterrey), éste se dio a la tarea de consultar la posibilidad de unificar los criterios de opinión de las cuatro provincias. El resultado fue que la Diputación Provincial establecida en Monterrey se pronunció por aspectos similares a los de la Junta de Saltillo del día anterior, aunque al parecer no tan radicales. ${ }^{59}$ Los postulados de la Diputación regiomontana fueron:

1) Se adopta la forma federal de gobierno bajo la cual se establecería un estado libre y soberano integrado a los demás de la nación mexicana de acuerdo con una constitución federal.

2) Se reconoce al Congreso restaurado sólo en su calidad de cuerpo destinado a convocar a uno nuevo. Se le confieren facultades para realizar solamente aquellas funciones que no estuvieran en oposición al sistema federal.

3) Se reconoce al Supremo Poder Ejecutivo como gobierno provisional de la nación, siempre y cuando en sus funciones no se oponga al sistema federal.

59 Según el padre Mier, la declaración en favor de la república federal fue aplaudida por el Congreso, aunque se reprobó la conducta de Saltillo y Monclova. Tal parece que la reprobación que se hizo de estas últimas dos villas se debió a la obstinación de Saltillo en no obedecer a la Dijutación establecida en Monterrey y al mantenimiento de la junta de Monclova aun después de instalada esta última. Véase carta del 19 de julio de 1823 , en Diez cartas, 1940, p. 14 (carta 4). 
4) El gobierno de Felipe de la Garza se dedicaría a buscar el bienestar de las cuatro provincias. ${ }^{60}$

Así, a partir de inicios de junio de 1823 la correspondencia entre el centro del país y las provincias norientales se hizo desde Monterrey y por parte de Felipe de la Garza. Esto se manifiesta en la serie de comunicaciones que este jefe hizo a Lucas Alamán sobre el fin de las desavenencias entre la Diputación Provincial en Monterrey y el Ayuntamiento de Saltillo, así como sobre la adhesión de ambas a la forma de gobierno republicana federada y sobre las atribuciones del Congreso restablecido. ${ }^{61}$

Por otro lado, sin embargo, sobre la unión de las cuatro provincias en un solo estado surgieron algunas diferencias con el centro político del país. En una comunicación del 6 de junio de 1823, el Ayuntamiento de Monterrey comunicó a Lucas Alamán, ministro de Relaciones Interiores y Exteriores, que Coahuila invitaba a Nuevo León y a Nuevo Santander a formar un solo estado soberano de las cuatro provincias, para lo cual se convocaba a una junta general (Felipe de la Garza lo llamó "congreso provincial", e incluso se llegó a elaborar el misterioso "Plan sobre las nuevas bases de la constitución de aquellas provincias"). ${ }^{62}$ Más de

60 Benson, Diputación, 1994, p. 197.

${ }^{61}$ Véanse al respecto los siguientes documentos: Felipe de la Garza a Lucas Alamán, Monterrey, 6 de junio de 1823; Lucas Alamán a la secretaría del Soberano Congreso, México, 28 de junio de 1823; Lucas Alamán a Felipe de la Garza, México, 28 de junio de 1823 en AGN, Gobernación, sin sección, caja 43, exp. 9, fs. 272-277.

62 El Ayuntamiento de Monterrey a Lucas Alamán, Monterrey, 6 de junio de 1823 en AGN, un mes después, Alamán respondió que no se podía aceptar el procedimiento de una junta general de las cuatro provincias nororientales pues

el voto de los pueblos y la voluntad política ha[n] sido completamente satisfechos [...], se ha dictado una convocatoria la más liberal y se ha recibido con júbilo y gratitud por la totalidad de las provincias, cuando el soberano Congreso y el Supremo Poder Ejecutivo se han pronunciado de un modo terminante a favor de la federación que nadie osa contradecir, y cuando en fin nos hallamos en vísperas de constituirnos. 63

Por otro lado, fray Servando también comunicaba al Ayuntamiento de Monterrey sobre la vergüenza que pasó cuando se presentó la propuesta de formar una sola provincia porque "¿a dónde iríamos a parar si a cada provincia se le antojase constituirse sin que el Congreso Constituyente de la nación señalase las bases para uniformar el sistema?". La respuesta a esta pregunta, señala el prelado, sería la anarquía y la guerra civil, por lo que desde el gobierno general se enviaba la orden a Felipe de la Garza (que prefiere "las ideas del señor Ramos a las de aquel a

Gobernación, sin sección, caja 43, exp. 9; Benson, Diputación, 1994, pp. 197-198 y 198n.

${ }^{63}$ Lucas Alamán al Ayuntamiento de Monterrey, México, 19 de julio de 1823 en AGN, Gobernación, sin sección, caja 43, exp. 9. La respuesta aparentemente tardada de Alamán se debió a que el ministro respondió a la comunicación del Ayuntamiento de Monterrey hasta después de haber leído la minuta de la sesión que celebrara la Diputación Provincial el 27 de junio anterior. 
quien debe su puesto") para que detenga dicho plan. ${ }^{64}$

La respuesta de Alamán y la carta de Mier al Ayuntamiento de Monterrey muestran la necesidad de que no se formen juntas para determinar si las provincias siguen unidas o no al centro. ${ }^{65}$ Resultaba innecesario, y hasta ilegal, ${ }^{66}$ pues todo lo que se pedía lo habían otorgado el Congreso y el ejecutivo. En primer término el decreto del 21 de mayo, que reconocía la nece-

${ }^{64}$ Diez cartas, 1940, p. 14 (carta 4).

65 Es probable que, como dice Benson, Alamán tuviera cierta aversión a la idea de la "junta", pues le traía recuerdos de lo que sucediera en 1808 en España y en la ciudad de México, en el sentido de que estos cuerpos reclamaban para sí la totalidad de la soberanía, misma que, tratándose de las provincias norteñas podía convertirse en un forma de secesión. Benson, Diputación, 1994, pp. 25-26.

66 De hecho, según un decreto de finales de abril, cuando se formaton las diputaciones de Nuevo Santander, con asiento en San Carlos, y de Nuevo León, Coahuila y Texas, con asiento en Monterrey, se estipuló que debían cesar todas las juntas gubernativas. $Y$ la propuesta que había recibido la Diputación Provincial y el Ayuntamiento de Monterrey provenía precisamente de una de estas juntas, la de Monclova. Dictamen de la comisión de Gobernación sobre la petición de Mier, México, 9 de abril de 1823, en AGN, Gobernación, sin sección, caja 45, exp. 11. Por otro lado, cuando Felipe de la Garza comunicó sobre la propuesta de la Junta de Monclova, Alamán, escribió: "[...] el gobierno no puede reconocer tales corporaciones [se refiere a la Junta de Monclova] que la Constitución no conoce, que las circunstancias pudieron hacer necesarias pero que han mandado cesar la autoridad de la representación nacional". Felipe de la Garza a Lucas Alamán, Monterrey, 27 de junio de 1823 en AGN, Gobernación, sin sección, caja 43, f. 217. sidad de formar un nuevo congreso. En segundo término, el decreto del 17 de junio que estipulaba la convocatoria y las bases para la elección de dicho congreso. En éstas, el fundamento de la elección sería la población, y no unas juntas, como lo que sugería Coahuila o la que se reuniera en Celaya en 1 de julio de ese año. ${ }^{67}$ Además, Alamán señala al Ayuntamiento regiomontano que el Supremo Poder Ejecutivo se había pronunciado por el sistema federal; prueba de ello había sido que el levantamiento de Santa Anna se había terminado y que la misma Junta de Celaya se había disuelto. ${ }^{68}$ Por último, el gobierno central había autorizado a las diputaciones provinciales para velar

67 No creo que Coahuila y Celaya, y otros "acuerdos interprovinciales" se pronuncjaran expresamente por una designación "electoral" realizada por las juntas. La idea me la sugiere, por una parte, la fuerte oposición de Lucas Alamán a este tipo de reuniones; en segundo término, también me lo sugiere la idea de Barragán de que el decreto del 17 de junio estaba redactado cle tal forma que se eliminara la posibilidad de que el nuevo congreso fuera una reunión de "delegados" provinciales (como al parecer lo pedía Guadalajara) y que en cambio fuera una "elección de representantes de la población, y a través de ésta [de] representantes de toda la nación". Barragán, Introducción, 1994, pp. 175-176, también a Ferrer, Formación, 1995, pp. 143-146.

${ }^{68}$ El 3 de junio anterior, en San Luis Potosí, Santa Anna se había pronunciado en favor del federalismo (se autodenominó "protector de la federación de las provincias"). Por otro lado, la junta de Celaya fue una reunión celebrada el 1 de julio en la que participó un representante de Santa Anna así como militares de las provincias de Querétaro, San Luis, Michoacán y Guanajuato. En esta junta se decidió defender el sistema federal y apoyar al supremo poder ejecutivo, no pro- 
sobre los fondos de provincia; e incluso para poder suspender a los empleados y proponer ternas para la designación de empleos civiles, políticos, de Hacienda y judiciales. ${ }^{69}$ Por todas estas razones, tanto el ministro del Interior como fray Servando pedían al Ayuntamiento de Monterrey que no hiciera caso a las peticiones de Coahuila de formar una junta especial de las cuatro provincias, con el fin de no caer en la absoluta anarquía, tal y como había sucedido en Colombia y Buenos Aires. ${ }^{70}$

ponían la formación de un nuevo congreso, y convocaban a las cuatro provincias a que trabajaran conjuntamente. Precisamente el 1 de julio Santa Anna cesó su rebelión en contra de las autoridades centrales. Según Benson, la razón de esto fue que el veracruzano se dio cuenta de lo inútil de su rebeldía por lo que intentó una salida airosa, alegando que él quedaba satisfecho con el decreto del 17 de junio. La junta de Celaya, por su parte, se disolvió ante la pérdida de apoyo militar de Santa Anna. Benson, Diputación, 1994, p. 208; también Jiménez, Planes, 1987, pp. 199-200.

69 Esta última "concesión" del supremo poder ejecutivo a las provincias se refiere al decreto del 11 de julio de 1823 que en su exposición de motivos hace hincapié sobre "la conveniencia que resulta a la nación de que las diputaciones provinciales tengan más extensión en sus atribuciones administrativas que las que les concede la Constitución española que rige". La comisión de gobernación a Lucas Alamán, México, 11 de julio de 1823 en AGN, Gobernación, sin sección, caja 44, exp. 17.

${ }^{70}$ Lucas Alamán al Ayuntamiento de Monterrey, México, 19 de julio de 1823 en AGN, Gobernación, sin sección, caja 43, exp. 9. Sobre esta última provincia, Alamán se refiere a la convocatoria que en 1821 hiciera el gobernador de la provincia de Córdoba para la formación de un Congreso Constituyente. Con el fin de evitar un mayor peso político de los cordobeses, la provin-
La invitación de la que hablaba el Ayuntamiento de Monterrey provenía de Coahuila (según los documentos había sido extendida desde Monclova) y tal parece que fue elaborada, o cuando menos ideada, por Miguel Ramos Arizpe, de quien recelaba el padre Mier porque tenía meses organizando un movimiento en las provincias nororientales que parecía separatista. Esta apariencia era la que mostraban los acontecimientos vistos desde la ciudad de México; por ejemplo, en la sesión de la Diputación Provincial, celebrada en Monterrey el 27 de junio, Felipe de la Garza se quejaba de que "algunos opinan [que estas provincias] se han separado del centro de unidad y reconocimiento al soberano Congreso y Supremo Poder Ejecutivo". La causa de esta afirmación era evidente, ¿qué mensaje se daba cuando una de las cuatro provincias nororientales deseaba formar una sola aludiendo que unidas se podían defender con más facilidad, precisamente cuando se sentían amenazadas por el pronunciamiento santannista del 3 de junio anterior? ${ }^{71}$ Por otro lado, en los meses de mayo y junio de 1823

cia de Buenos Aires retiró a sus representantes con lo cual el Congreso cordobés perdió su columna vertebral. Aunque el caso no es idéntico, toda vez que las provincias nororientales no eran (por mucho) ricas, la formación de juntas interprovinciales presentaba la posibilidad de que hicieran lo mismo que hizo la provincia de Buenos Aires en 1821. Al respecto, véase Burgin, Aspectos, 1975, pp. 122-124.

71 Véase el pronunciamiento del Ayuntilmiento de Monterrey, Monterrey, 30 de junio de 1823 en AGN, Gobernación, sin sección, caja 43, exp. 9, fs. 279:281. 


\section{SECUENCIA}

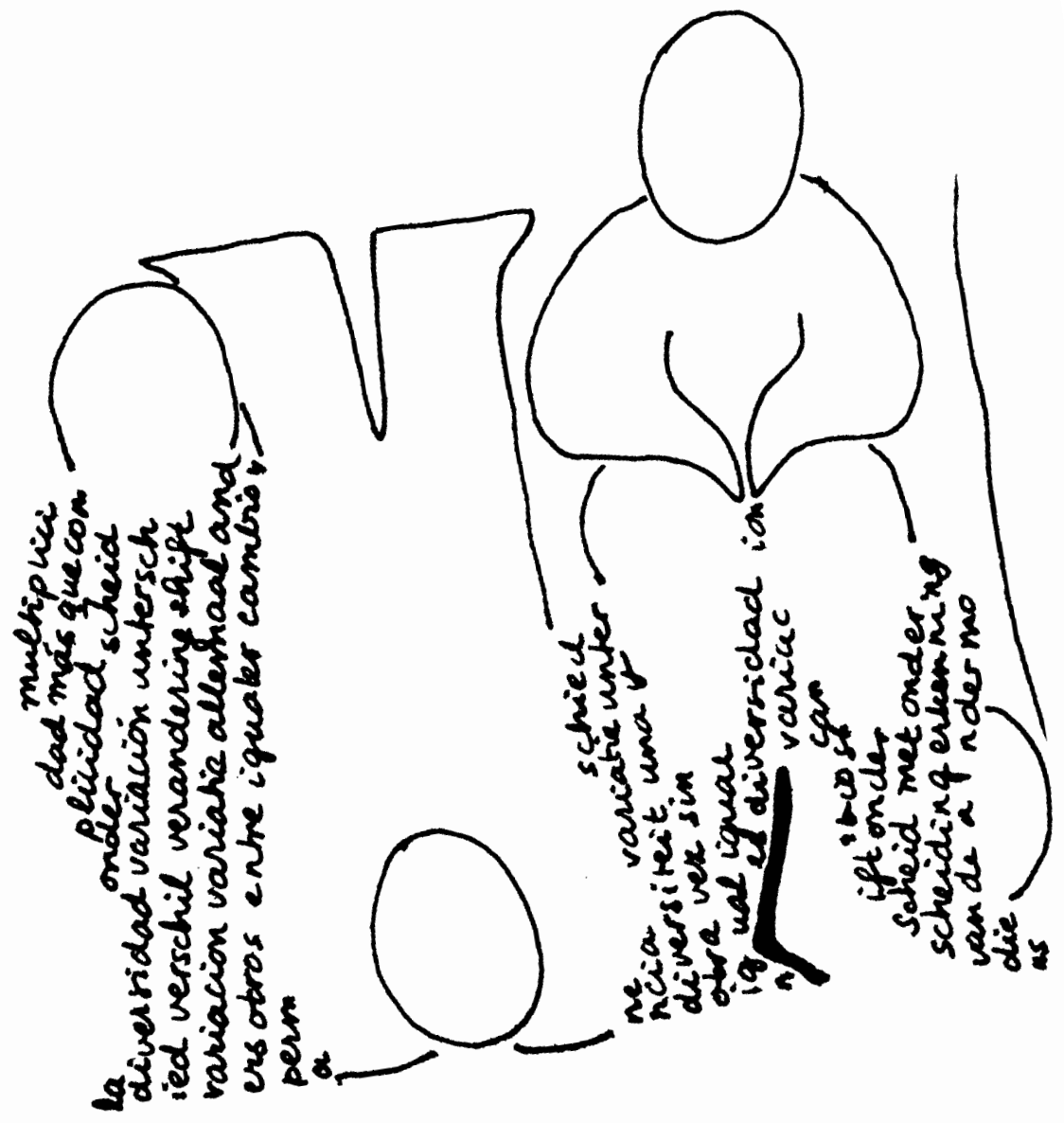


aparecieron en el norte dos proyectos de constitución: al primero, ya mencionado arriba, se le denominó "Plan sobre las nuevas bases de la constitución de aquellas provincias"; el segundo era el "Plan del gobierno federal" de Esteban Austin, que fue redactado como una constitución. Aunque es indudable que, como dice Benson, en la época "eran muy frecuentes las referencias inexactas y las malas interpretaciones", 72 poca duda cabe de que la queja de De la Garza tenía buenas bases; unirse para defenderse de un enemigo y escribir (y al parecer hasta imprimir) una constitución, en tiempos en que todavía no se elaboraba la constitución general de la república, sonaba mucho al deseo de formar otro país.

Según el padre Mier, quien estaba detrás de todo este movimiento era Miguel Ramos Arizpe. ${ }^{73} \mathrm{El}$ intento de Mier de colocar a Felipe de la Garza en la jefatura política para controlar a Ramos Arizpe había fallado por razones arriba expuestas. Aun así, Mier no estaba derrotado y aún contaba con fuertes relaciones en la ciudad de México; además, la situación de las provincias

72 Benson, Diputación, 1994, p. 198n.

${ }^{73}$ En 1824 Miguel Ramos Arizpe comentaba sobre el "maridaje forzoso" que habían tenido que vivir Nuevo León y Coahuila; él, por su parte, defendió la unión de las cuatro provincias (tres cuando Nuevo Santander se separó) por cuidar la posición coahuilense. $Y$ es que Ramos Arizpe reconocía que su estado natal tenía pocos recursos como para ser estado de la federación, por lo que si se quedaba solo terminatía por ser un territorio a merced de un congreso y un ejecutivo muy lejanos y preocupados por cosas de mayor envergadura. Ramos, "Informe", 1989, pp. 78-79. nororientales que se percibía desde la ciudad de México ayudaba, y mucho, a los propósitos de Mier. Fue así que el 25 de junio, en sesión secreta, el Congreso votó por que se estableciera una diputación en cada una de las Provincias Internas de Oriente y, en contra de De la Garza, por la separación del mando político y el militar. La respuesta de las provincias, que en realidad nunca habían tenido la intención de separarse del resto del país, ${ }^{74}$ fue la de esperar a que se desenvolvieran los acontecimientos en el Congreso. ${ }^{75}$

${ }^{74} \mathrm{Al}$ respecto (si le hemos de creer) Felipe de la Garza comentaba al ministro del Interior: "Las autoridades nunca propendieron a formar un estado absolutamente libre e independiente de la nación mexicana, muy al contrario, estas autoridades que se pronunciaron por el sistema federado en circunstancias muy delicadas [...] protestaron su obediencia y reconocimiento de la nación [y] no podrán ser jamás desconocidos por patriotas muy beneméritos que no aspiran a otra cosa que a la felicidad pública y de ningún modo a procurar medios de que ciertamente no tienen necesidad, ni a los demás conceptos equivocados que se han atribuido a sus procedimientos." Felipe de la Garza a Lucas Alamán, San Carlos, 16 de agosto de 1823 , en AGN, Gobernación, sin sección, caja 43 , exp. 8 , fs. 214-215.

75 Benson, Diputación, 1994, pp. 198-199. Sobre estas disposiciones, Mier comunicaba al Ayuntamiento de Monterrey: "así quedaremos libres de saltilleros, que aportarán a los empleos de su patria y nada más. El señor Garza cuidará de sus soldados y concluido." Diez cartas, 1940, p. 15 (carta 4). 
EL ASUNTO DE LAS ELECCIONES

\section{AL SEgundo Congreso CONSTITUYENTE}

De acuerdo con el artículo 81 del decreto de convocatoria a las elecciones del Congreso Constituyente, cada una de las diputaciones provinciales debía hacer llegar a los ayuntamientos las instrucciones de dicho proceso. Consecuentemente, el 10 de julio de 1823 la Diputación Provincial de Nuevo León, Coahuila y Texas comenzó a circular el método para verificar las elecciones. ${ }^{76}$ ¿Qué características locales tenía este método? De acuerdo con la comisión/ junta preparatoria designada por la $\mathrm{Di}$ putación Provincial, la primera duda que surgía al cumplir con lo estipulado por el decreto del 17 de junio era si sus trabajos comprendían a las tres provincias o sólo a la de Nuevo León, con juntas similares para Texas y Coahuila. La duda surgía, dice la comisión, de una aparente contradicción entre los artículos 81 y 83 del decreto de convocatoria. El primero de estos artículos indicaba que un decreto posterior arreglaría las disposiciones para la instalación de las juntas preparatorias; el otro daba a las diputaciones provinciales la autoridad total para realizar dicha instalación. ${ }^{77}$ Ante esta disyuntiva, la comisión aconseja separarse de la letra de la convocatoria y recomienda a la Diputación Provincial que se haga cargo

${ }^{76}$ La Diputación Provincial en Monterrey al Ayuntamiento de Monterrey, Monterrey, 10 de julio de 1823 en AGN, Gobernación, sin sección, caja 43, exp. 8, fs. 223-224.

77 Dublán y Lozano, Legislación, 1876, vol. 1, p. 656. de las elecciones en la totalidad de la demarcación "porque en V. E. están los diputados de todas las provincias y aun de los pueblos principales que las componen". El problema, empero, estaba en qué hacer con la oposición que en todo caso presentarían las provincias de Texas y Coahuila.

La comisión no se hace cargo de la provincia de Texas por estar sumamente desatendida y despoblada. Al caso de Coahuila, empero, dedica varios comentarios. Primeramente, hace un diagnóstico de la situación de esta provincia en la Diputación Provincial; cuenta con tres diputados que representan a Saltillo, Monclova y Parras. Sin embargo, a pesar de que son diputados electos por la mayoría, no por ello conocen las necesidades de los otros pueblos de la provincia. En este sentido, la comisión señala que los pueblos también tienen derechos y por tanto la Diputación Provincial debe respetarlos en lo concerniente a la asignación de sus electores. Esto es a todas luces imprescindible si no se desea que se repita lo que sucedió con Saltillo. Con el fin de ejemplificar la situación de algunos pueblos de Coahuila, la comisión presenta un ejemplo: Parras tiene una población de 14329 habitantes; según reinterpretación del arrículo 30 de la convocatoria, le corresponde un elector primatio por cada 500 habitantes. Según la reparticion de distritos realizada en 1820 , los electores tendrían que ir hasta Saltillo (lo que significaría un viaje de 160 leguas de ida y vuelta), y si los electores son labradores, tienen que dejar su trabajo, por lo que el costo total de tener electores primarios sumaría 1700 pesos. 
En igual o peor situación que Parras se encuentran otros pueblos de las provincias, por lo que la comisión recomienda una redistritación.

En seguida la comisión procede a exponer el reglamento; para ello, y de acuerdo con el artículo tercero de la convocatoria, se basa en los trabajos de la junta preparatoria de 1820 . En contra de la sugerencia de redistritación, la comisión señala que

por ahora no perjudica esto a las provincias [se refiere al artículo tercero] pues en cualquier evento había de ser uno mismo el resultado de que cada una de ellas diese un diputado nada más. ${ }^{78}$

El reglamento que forma parte de la instrucción se divide en cuatro postulados. El primero divide a la provincia de Nuevo León en cinco partidos: Monterrey; Cadereyta; Pilón; Linares, y Boca de Leones. El segundo postulado hace la división correspondiente a la provincia de Coahuila en cuatro partidos: Monclova; Río Grande; Saltillo, y Parras. A la provincia de Texas, contemplada en el tercer postulado, se le da un tratamiento especial acorde con lo estipulado en el artículo 67 de la convocatoria, que señala que si la provincia no alcanza los cinco electores secundarios para la elección de un diputado, nombrará cinco electores "formando al efecto otras tantas secciones

78 Instrucción de la comisión/junta preparatoria de la Diputación Provincial en Monterrey para las elecciones a diputados ante el Congreso Constituyente, Monterrey, 5 de julio de 1823, en AGN, Gobernación, sin sección, caja 43, exp. $8, \mathrm{f}$. 233. de población proporcionalmente iguales". ${ }^{79}$ Así, la división de Texas sería en cinco secciones: Bahía del Espíritu Santo; El Colorado y San Antonio Béjar, que, a juicio del Ayuntamiento, se dividiría en tres. ${ }^{80}$ Por último, la instrucción incluye una nota, en la que señala que los ayuntamientos de las cabeceras de partido serían los encargados de notificar a cada pueblo cuántos electores primarios les correspondían, de modo que entre todos no den más electores que los asignados en el plan.

De acuerdo con esta instrucción, con el decreto de convocatoria del 17 de junio anterior, y con las elecciones que se realizarían en el mes de agosto siguiente, Nuevo León, Coahuila y Texas quedarían, cada uno, con un diputado propietario y un suplente.

El asunto de la instrucción distribuida por una "junta preparatoria" de la Diputación Provincial dio origen a fuertes recriminaciones entre ésta y el Ayuntamiento de Monterrey. Este último señalaba que, de acuerdo con los artículos 16 y 17 del capítulo 3 del decreto del 23 de junio de 1813 , tal distribución sólo correspondía al jefe político, por lo que en tres ocasiones regresó la instrucción que la Diputación Provincial le había enviado para que arreglara la elección de acuerdo con la ley. ${ }^{81} \mathrm{El}$ argumento del Cabildo

79 Dublán y Lozano, Legislación, 1876, vol. 1, p. 655 .

${ }^{80}$ Instrucción de la comisión, Monterrey, 5 de julio de 1823 en AGN, Gobernación, sin sección, caja 43, exp. 8, f. 233.

${ }^{81}$ Al parecer, Felipe de la Garza no se encontraba en Monterrey como para poder distribuir la instrucción tal y como lo estipulaba el ordena- 
era que no le pertenecía emprender tal arreglo, y si la ley de convocatoria del 17 de junio señalaba que en un futuro se arreglaría este asunto, entretanto el Ayuntamiento se defendía y apoyaba en la ley gaditana aún vigente. La Diputación, por su parte, quiso imponet su voluntad señalando que el Ayuntamiento debía obedecerla por el hecho de que éste tenía menor representación y por tanto menos poder. Aunque los miembros del Ayuntamiento se sintieron sumamente agraviados por la respuesta de la Diputación, solamente respondieron que no deseaban obligar a ésta a nada, sino que se cumpliera la ley; por tanto, varios días después el Ayuntamiento cedió aludiendo al artículo 19 del capítulo 1 del decreto del 23 de junio de 1813 que señalaba que en defecto del jefe político, los alcaldes primeros de las cabeceras de distrito podían circular las órdenes y decretos;

miento gaditano. Fray Servando sugiere que De la Garza se hallaba planeando sostener la junta general planeada por Ramos Arizpe, un hecho que sin duda sería causa de su destitución y hasta de la marcha del ejército sobre la región. Entretanto, quien firmaba la correspondencia con el gobierno general era José Antonio Rodríguez, quien todos suponían el decano de la diputación. Sobre la situación del mando en la diputación en los primeros días de agosto de 1823, Mier comenta: "Nosotros [...] viendo firmadas por un señor Rodríguez las actas de la Diputación, creíamos que sin duda era el más antiguo y el ministro le había escrito retuviese el mando político aun y cuando volviese Garza, y lo mismo a [Juan] Echandia para que retuviese el militar hasta que se provean en propiedad las dos plazas." Lo que de hecho implicaba la destitución de Felipe de la Garza. Al respecto, véase carta del 9 de agosto de 1823, en Diez cartas, 1940, p. 17 (carta 5). de esa forma el Ayuntamiento de Monterrey, al igual que el resto de las cabeceras, distribuyeron la información contenida en la instrucción. ${ }^{82}$

El problema entre la Diputación y el Ayuntamiento podría parecer trivial; sin embargo, muestra claramente un hecho que varios días después reveló la Diputación Provincial al ministro Lucas Alamán: "Esta diputación ya no es sino una sombra de autoridad, reducida casi a un estado de nulidad e impotencia moral." 83 Este hecho se confirmó a inicios de septiembre con la disolución de esta junta, según el decreto del 18 de agosto anterior expedido por el Congreso general, en donde se formaban diputaciones locales en Nuevo León, Coahuila y Texas. ${ }^{84}$ En su lugar, a mediados del mes de septiembre de 1823, quedó la Diputación Provincial electa según la ley del 17 de junio anterior. ${ }^{85}$

82 Correspondencia entre al Ayuntamiento de Monterrey y la Diputación Provincial en Monterrey, $12,14,15,21$ y 24 de julio de 1823 en AGN, Gobernación, sin sección, caja 43, exp. 8, fs. 233 , 235-238, 240-241, 246-247, 250, 251, 253.

83 La Diputación Provincial en Monterrey a Lucas Alamán, 18 de julio de 1823 en AGN, Gobernación, sin sección, caja 43, exp. 9, f. 244.

${ }^{84} \mathrm{El}$ problema con el Ayuntamiento se había arreglado, y para finales de agosto se celebraban ordenadamente las elecciones. Las juntas que había en Monclova y en Texas también se habían disuelto. Véase José Antonio Rodríguez al Lucas Alamán, Monterrey, 29 de agosto de 1823 en AGN, Gobernación, sin sección, caja 43, exp. 8, fs. 223224.

${ }^{85}$ Las elecciones primarias se celebraron el 8 de agosto; las secundarias el 14. Alessio, Coabuila, 1940-1946, vol. 1, p. 153. Las elecciones provinciales se realizaron después de la primera se- 


\section{CONCLUSIONES}

Los cruciales seis meses comprendidos entre la promulgación del Plan de Casa Mata y la elección de la nueva Diputación Provincial de Nuevo León en agosto de 1823 confirman, en el caso de esta provincia, muchas de las hipótesis que se han planteado sobre el periodo. Por una parte, se observa cómo, paulatinamente, va perdiendo poder el centro político de la nación. En los hechos, esta pérdida de poder se manifiesta en la formación de tres juntas -Monterrey, Saltillo y Monclova- que son la expresión de la época que tenían las elites regionales para cuidar el bien común ante el definitivo resquebrajamiento del control político de la ciudad de México sobre las regiones.

Por otro lado, e independientemente de la pugna entre Saltillo y Monterrey sobre el asiento de los poderes regionales, observamos también que cada una de estas juntas tenía ideas particulares sobre cómo debía conformarse el país. Asî, por una parte, las juntas sal-

mana de septiembre. Felipe de la Garza a José Antonio Rodríguez, s. c., 6 de septiembre de 1823 en AGN, Gobernación, sin sección, caja 43, exp. 8, f. 229. La nueva Diputación Provincial estuvo formada por: Eusebio Gutiérrez, Juan José de la Garza, Joaquín García, Pedro González, Andrés Sobrevilla, Bernardo Guimbarda y Pedro de la Garza. Al parecer, la jefatura política estaba en manos de José Antonio Rodríguez. Benson, Diputación, 1994, pp. 214, 250-251. El diputado provincial por Nuevo León ante el llamado segundo Congreso Constituyente fue fray Servando Teresa de Mier. Véase Moreno, Catálogo, 1975 , pp. 896-897. tillense y de Monclova, con el apoyo de Miguel Ramos Arizpe, pugnaban por lo que Di Tella llama un "potencial federalismo", mismo que se hizo evidente en la propuesta de la Junta de Monclova para que se formara un acuerdo regional amplio muy similar al que por esos meses se buscaba en Jalisco y el Bajío; este "acuerdo" implicaba la formación de una sola provincia de Coahuila-Texas-Nuevo León. Por su parte, la Diputación Provincial con asiento en Monterrey, siguió la línea del liberalismo moderado, con tendencias centralistas y que propugnaba por la permanencia del antiguo Congreso Constituyente; un hecho que se reflejó fielmente en el caso de la Diputación regiomontana, que fue la misma de tiempos de Iturbide. La línea de la Diputación Provincial nororiental fue en buena medida alimentada desde la ciudad de México por el padre Mier.

A fin de cuentas, la propuesta de las juntas coahuilenses - de formar una' sola provincia nororiental- no se llevó a cabo, lo que estuvo de acuerdo con la posición regiomontana. Sin embargo, en el caso de los miembros de la Diputación Provincial, y al igual que lo que sucedía en la ciudad México con el Congreso, éstos debieron convocar a elecciones para un nuevo cuerpo legislativo local. Por tanto, los estados de Coahuila-Texas y de Nuevo León, que vinieron a formarse en el curso del siguiente año, tuvieron su origen en la contemporización que se dio entre los grupos de Ramos Arizpe y Teresa de Mier en los cruciales seis meses de la primavera y verano de 1823 . 


\section{SECUENCIA}

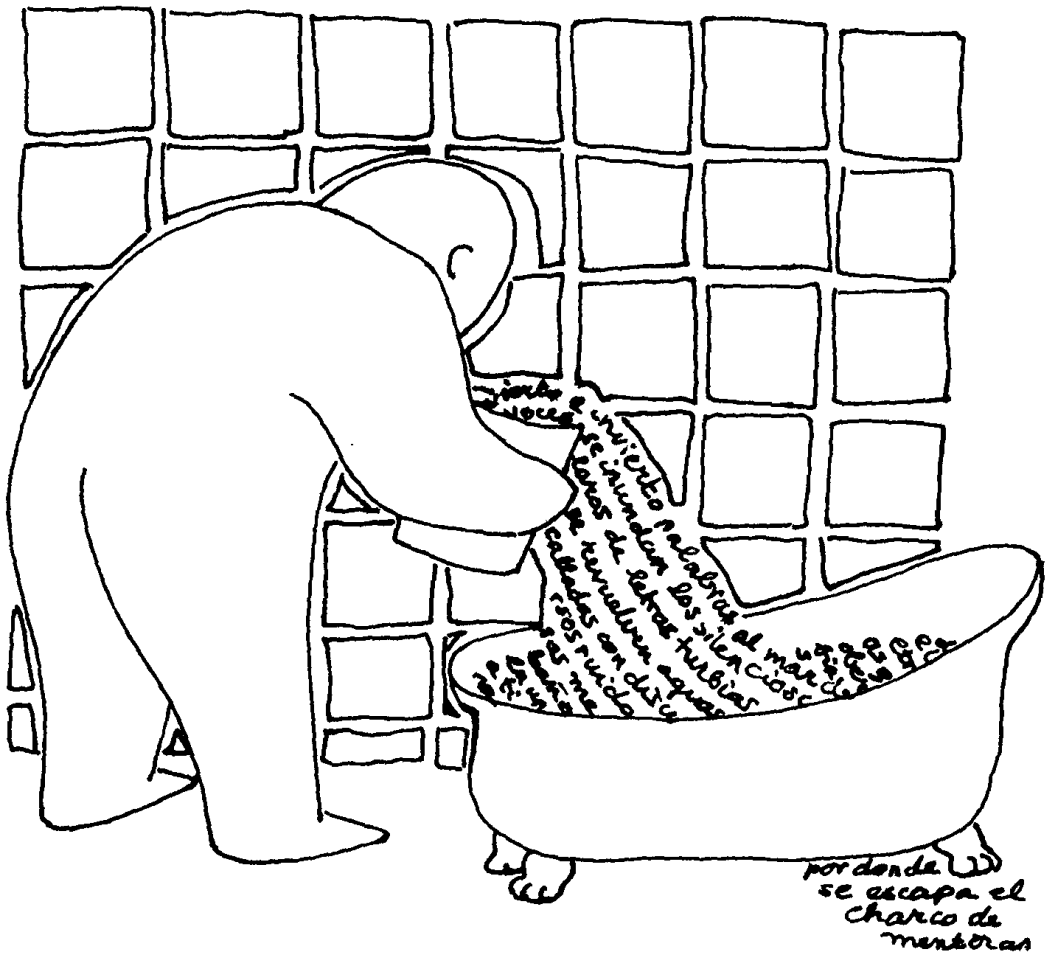




\section{ARCHIVOS}

AAM Actas de Cabildo en el Archivo del Ayuntamiento de Monterrey

AGENL Archivo General del Estado de Nuevo León.

AGN Achivo General de la Nación, México.

\section{BIBLIOGRAFÍA}

-Actas constitucionales mexicanas (1821-1824), edición de José Barragán Barragán, Universidad Nacional Autónoma de México, 2a ed., México, 1980, 8 vols.

-Alamán, Lucas, Historia de México, desde los primeros movimientos que prepararon su independencia en el año de 1808 hasta la época presente, Fondo de Cultura Económica/Instituto Cultural Helénico (Facsímil de la edición de 1852), México, 1985, 5 vols.

-Alessio Robles, Vito, Coabuila y Texas desde la consumación de la independencia basta el Tratado de Paz de Guadalupe Hidalgo, s.p.i., 1940-1946, 2 vols.

-Barragán Barragán, José, Introducción al federalismo (la formación de los poderes, 1824), Universidad de Guadalajara, Guadalajara, 1994.

-Benson, Nettie Lee, La Diputación Provincial y el federalismo mexicano, El Colegio de México/Universidad Nacional Autónoma de México, 2a ed. en español, México, 1994.

-Burgin, Miron, Aspectos económicos del federalismo argentino, Ediciones Solar, Buenos Aires, 1975.

-Bustamante, Carlos María de, Diario bistórico de México, ed. de Rina Ortiz Peralta, introducción de Manuel Calvillo, SEP/INAH, México, 1980,3 vols.

-Diez cartas, hasta boy inéditas, de fray Servando Teresa de Mier. Se publican por iniciativa del C. alcalde primero, prof. Manuel Flores, edi- ción de Alberto Galván y Santiago Roel, Monterrey, 1940.

-Di Tella, Torcuato S., Política nacional y popular en México, 1820-1847, Fondo de Cultura Económica, México, 1994.

-Dublán, Manuel y José María Lozano, Legislación mexicana o colección completa de las disposiciones legislativas expedidas desde la independencia de la repuiblica, Imprenta del Comercio, México, 1876.

-Ferrer Muñoz, Manuel, La formación de un Estado nacional en México. El imperio y la república federal: 1821-1835, IIJ-UNAM, México, 1995.

-Green, Stanley, The Mexican Republic. The First Decade, 1823-1832, University of Pittsburgh Press, Pittsburgh, 1987.

-Hernández y Dávalos, J. E., Historia de la guerra de independencia de México [edición facsimilar de la de 1878], Instituto Nacional de Estudios Históricos de la Revolución Mexicana, México, 1985, 6 vols.

- Jiménez Codinach, Guadalupe, Planes en la nación mexicana. Libro uno: 1808-1830, Senado de la República, México, 1987.

-Lemus, Pedro, "Parte del comandante militar de la provincia del Nuevo Reino de León, al Excmo. Sr. general en jefe del ejército libertador, sobre el estrepitoso alzamiento de los serviles contra los liberales de Monterrey, la noche del 30 de abril último", Imprenta de Estrada, San Luis Potosí, 1823.

-Mecham, J. Lloyd, "The Origins of Federalism in Mexico", Hispanic American Historical Review, vol. 18, 1938, pp. 164-189.

-Moreno Valle, Lucina, Catálogo de la colección Lafragua, 1821-1853, IIB-UNAM, México, 1975.

-Ramos Arizpe, Miguel, "Informe a los ayuntamientos y pueblos de Coahuila" en Eduardo Enríquez Terrazas y José Luis García Valero (comps.), Coabuila: textos de su bistoria, Gobierno del Estado de Coahuila/Instituto Mora, México, 1989, pp. 75-82. 